\title{
Human head orientation and eye visibility as indicators of attention for goats (Capra hircus)
}

\author{
Christian Nawroth ${ }^{\text {Corresp., }}{ }^{1}$, Alan G. McElligott ${ }^{\text {Corresp. } 1}$ \\ 1 Biological and Experimental Psychology, School of Biological and Chemical Sciences, Queen Mary University of London \\ Corresponding Authors: Christian Nawroth, Alan G. McElligott \\ Email address: c.nawroth@qmul.ac.uk, a.g.mcelligott@qmul.ac.uk
}

Animals domesticated for working closely with humans (e.g. dogs) have been shown to be remarkable in adjusting their behaviour to human attentional stance. However, there is little evidence for this form of information perception in species domesticated for production rather than companionship. We tested domestic ungulates (goats) for their ability to differentiate attentional states of humans. In the first experiment, we investigated the effect of body and head orientation of one human experimenter on approach behaviour by goats. Test subjects $(\mathrm{N}=24)$ significantly changed their behaviour when the experimenter turned its back to the subjects, but did not take into account head orientation alone. In the second experiment, goats $(N=24)$ could choose to approach one of two experimenters, while only one was paying attention to them. Goats preferred to approach humans that oriented their body and head towards the subject, whereas head orientation alone had no effect on choice behavior. In the third experiment, goats $(N=32)$ were transferred to a separate test arena and were rewarded for approaching two experimenters providing a food reward during training trials. In subsequent probe test trials, goats had to choose between the two experimenters differing in their attentional states. Like Experiment 1 and 2, goats did not show a preference for the attentive person when the inattentive person turned her head away from the subject. In this last experiment, goats preferred to approach the attentive person compared to a person who closed their eyes or covered the whole face with a blind. However, goats showed no preference when one person covered only the eyes. Our results show that animals bred for production rather than companionship show differences in their approach and choice behaviour depending on human attentive state. However, our results contrast with previous findings regarding the use of the head orientation to attribute attention and show the importance of cross-validating results. 
1 Human head orientation and eye visibility as indicators of attention for goats (Capra 2 hircus)

3 Christian Nawroth, Alan McElligott

4 Queen Mary University of London, Biological and Experimental Psychology, School of Biological

5 and Chemical Sciences, London, U.K.

6

7

8

9

10

11

12 Corresponding authors

13 Christian Nawroth

14 Email address: nawroth.christian@gmail.com

15 Alan McElligott

16 Email address: a.g.mcelligott@qmul.ac.uk 


\section{Abstract}

Animals domesticated for working closely with humans (e.g. dogs) have been shown to be remarkable in adjusting their behaviour to human attentional stance. However, there is little evidence for this form of information perception in species domesticated for production rather than companionship. We tested domestic ungulates (goats) for their ability to differentiate attentional states of humans. In the first experiment, we investigated the effect of body and head orientation of one human experimenter on approach behaviour by goats. Test subjects $(N=24)$ significantly changed their behaviour when the experimenter turned its back to the subjects, but did not take into account head orientation alone. In the second experiment, goats $(N=24)$ could choose to approach one of two experimenters, while only one was paying attention to them. Goats preferred to approach humans that oriented their body and head towards the subject, whereas head orientation alone had no effect on choice behavior. In the third experiment, goats $(\mathrm{N}=32)$ were transferred to a separate test arena and were rewarded for approaching two experimenters providing a food reward during training trials. In subsequent probe test trials, goats had to choose between the two experimenters differing in their attentional states. Like Experiment 1 and 2, goats did not show a preference for the attentive person when the inattentive person turned her head away from the subject. In this last experiment, goats preferred to approach the attentive person compared to a person who closed their eyes or covered the whole face with a blind. However, goats showed no preference when one person covered only the eyes. Our results show that animals bred for production rather than companionship show differences in their approach and choice behaviour depending on human attentive state. However, our results contrast with previous findings regarding the use of the head orientation to attribute attention and show the importance of cross-validating results. 
44

\section{Introduction}

Body and head orientation are an important component of social interaction and the ability to recognise different attentive states of conspecific or heterospecifics yields adaptive advantages in the contexts of predation, deception or cooperation (Emery, 2000). For example, gaze directed towards an individual might be considered as threat and elicit anti-predator response (Kummer, 1967). American crows (Corvus brachyrhynchos) have been shown to adjust their behaviour based on human gaze (Clucas et al., 2013). When an experimenter approached the subjects, crows fled sooner when the person was directly gazing at them compared to when gaze was averted. Jackdaws (C. monedula) showed similar avoidance behavior during an approach task. When an unfamiliar human paid attention to them, their time to approach a reward was higher compared to when the unfamiliar human looked away or had its eyes closed (von Bayern \& Emery, 2009). Beausoleil et al. (2006) investigated whether human staring altered the behaviour of domestic sheep (Ovis aries) compared with no human eye contact. They found that sheep glanced at the staring human's face more often and showed higher levels of locomotor activity. However, researchers did not find differences in fear-related behaviours. Research on wild and captive primates have shown that when they have the opportunity to steal from one of two experimenters, Rhesus monkeys (Macaca mulatta) and several species of lemurs choose to take food from an experimenter who was not looking at the reward (Flombaum \& Santos, 2005; Sandel, MacLean \& Hare, 2011). Being habituated to humans and knowing that people regularly deliver food, individuals might opt to position themselves to be seen by humans or to choose a person that pays attention towards them, expecting to receive a food reward or one with less delay. When they have to make a choice, captive chimpanzees (Pan troglodytes) have been found to prefer to beg from an attentive rather than an inattentive person (Bulloch, Boysen \& Furlong, 2008). 
68

69

Dogs (Canis familiaris) are assumed to be specifically attuned to human cues due to their domestication history as companion animals (Hare et al., 2002). For example, they show great sensitivity to human communicative cues, such as human pointing and gazes, to find a reward in an object choice task (Agnetta, Hare \& Tomasello, 2000; Riedel et al., 2008). In these tasks, subjects have to choose between two or more containers while only one is containing food (Miklósi \& Soproni, 2006). However, domestic goats have also been shown to use a basic human pointing gesture, but nor head direction or gazes, to find a reward in this task (Kaminski et al., 2005; Nawroth, von Borell \& Langbein, 2015). Similar findings have been obtained for other domestic species, such as cats, Felis catus, (Miklósi et al., 2005), horses, Equus caballus, (Proops, Walton \& McComb, 2010; Proops et al., 2013). Dogs are also able to comprehend more complex gestures and can distinguish whether information is intended for them (Kaminski, Schulz \& Tomasello, 2012; Lakatos et al., 2012). They are also sensitive to the attentional stance of humans. When not allowed to obtain a reward in front of them, they disobeyed faster when the human was distracted or not looking at the dog (Call et al., 2003). When dogs had to choose between either a person that was looking at them versus a person that had turned their back to them, dogs approached the attentive experimenter (Udell, Dorey \& Wynne, 2011). But here again, horses (Proops \& McComb, 2010) and pigs, Sus scrofa, (Nawroth, Ebersbach \& von Borell, 2013) have been shown to express similar preferences.

We investigated the ability of goats to perceive information from human attentional states. Using a food-anticipating paradigm, Nawroth et al. $(2015,2016)$ found that goats adapted their anticipation behaviour depending on the presence or absence of an experimenter in general and his/her head and body orientation in particular. In these experiments, an experimenter remained for 30 seconds in an assigned posture before delivering a reward to the tested subject, and the goats' active anticipation and standing alert behaviour were analysed. The level of subjects' active anticipatory behaviour was highest when the experimenter looked in the direction of the test 
94 subject, and decreased with a decreasing level of attention paid to the subject by the

95 experimenter. Additionally, goats 'stared' (i.e., stood alert) at the experimental setup for

96 significantly more time when the experimenter was present but had his head and/or body directed

97 away from the subject. However, due to previous training, it was not clear if simple conditioned

98 responses were responsible for the goats' change in behaviour (Proops \& McComb, 2010).

99 Subjects may have learned that a certain posture of the experimenter (head and body oriented

100 towards subject) would yield a reward.

101

102 To cross-validate and extend these previous findings on goats' ability to differentiate between

103 human attentive states, we examined the approach and choice behaviour of goats towards

104 humans who were paying different degrees of attention to them. In an important contrast to

105 previous research on goats, these approach and choice tasks involved little or no task-related

106 learning prior to the actual test. In Experiment 1, goats had the opportunity to approach either an

107 attentive or inattentive person and their approach behavior (i.e. if they preferred to move into the

'attention window' of the human) was examined. We expected goats to move around the

experimenter when the person was not paying attention towards them. Being aware that both behavioural outcomes (moving around the human or not) require different amounts of energetic costs, we subjected goats to additional choice experiments. In Experiment 2 and 3, goats had to choose between an attentive versus an inattentive person. While Experiment 2 involved no

113 training and spontaneous choice behavior in the field, Experiment 3 was conducted in a separate

114 test arena to control in more detail for environmental factors. Being familiar with human presence, 115 we expected subjects to choose in a cooperative manner (i.e. choose the human that was paying 116 attention to them) because this would decrease a delay in potential reward delivery or grooming 117 events. 
118

119

120

121

122

123

124

125

126

127

128

129

130

131 The experiments were carried out at Buttercups Sanctuary for Goats, UK 132

133

134

135

136

137

138

139

140 Experiment 1.1: Body orientation

\section{Animals, materials \& methods}

\section{Ethical Note}

Animal care and all experimental procedures were in accordance with the ASAB/ABS Guidelines for the Use of Animals in Research (Association for the Study of Animal Behaviour, 2016). The study was approved by the Animal Welfare and Ethical Review Board committee of Queen Mary University of London (Ref. QMULAWERB032015). All measurements were non-invasive, and the experiment lasted no more than $10 \mathrm{~min}$ for each individual goat. If the goats had become distressed, the test would have been stopped.

\section{Subjects, housing and general procedure} (http://www.buttercups.org.uk). Goats were fully habituated to human presence because of previous research (e.g. Baciadonna et al., 2016; Nawroth, Brett \& McElligott, 2016). They were aged 2-14 years and of various breeds. Routine care of the animals was provided by sanctuary employees and volunteers. The goats had ad libitum access to hay and were not food restricted before testing. Subjects were tested from 12:00-16:00 in June - August 2015.

\section{Experiment 1: Approach behaviour in the field}

Procedure 
143 The experimenter approached a focal subject that was separated from other groups by about 5-

$14410 \mathrm{~m}$. He then proceeded to get its attention by calling 'Come here'. As soon as the goat

145 approached, a trial started. When the goat approached to about $2 \mathrm{~m}$ from the experimenter, the

146 person either stayed with his front and head oriented towards the subject ('front') or turned 180

147 degrees ('back'). During both conditions, the hands of the experimenter were oriented away from

148 the subject (behind the experimenter's back in the 'front' condition; in front of experimenter in the

149 'back' condition). A total of 29 trials were conducted. Five goats had to be excluded because they

150 stopped approaching the experimenter, leaving 24 successful approach trials. Twelve subjects

151 received the 'front' condition and the other 12 subjects received the 'back' condition. Goats were

152 never rewarded during trials.

153
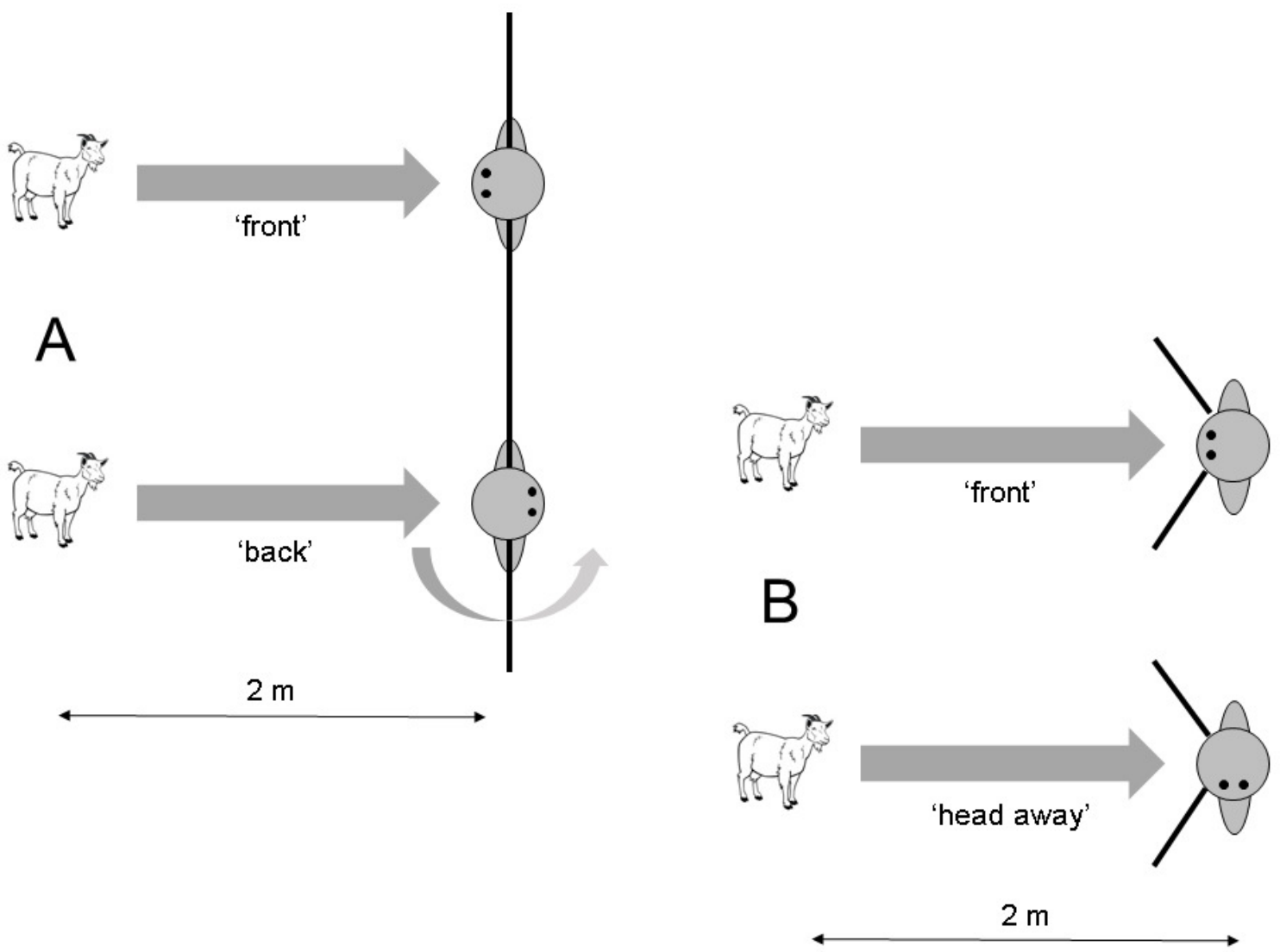
155 Figure 1. Setup of the approach task in a) Experiment 1.1 and b) Experiment 1.2. The black lines

156 close to the experimenter indicate threshold lines that were used to define a specific approach

157 behaviour. If a subject did not cross the line (and thus remained in front of it), it was scored as

158 'front approach'. If it crossed the line, it was scored as 'behind approach' (Experiment 1.1) or 'side

159 approach' (Experiment 1.2).

160

161

Data scoring and analysis

162 Approach behaviour of the goats was scored live. After a goat approached the experimenter to 163 approximately $1 \mathrm{~m}$, the experimenter scored the behaviour of the goats during the following 5 164 seconds. If a goat crossed the midline of the experimenter during these 5 seconds with its head 165 (threshold line; Figure 1a), this was scored as a 'behind approach'. If the goat remained in front 166 of the threshold line during these five seconds, this was scored as 'front approach'. Fisher's exact 167 test was used to compare the amount of both approach behaviours in the two different conditions. 168

Results

A strong difference in the approach behaviour between the two conditions was found for the 'front approach'. Whereas all 12 subjects in the 'front' condition stayed in front of the threshold line for $5 \mathrm{~s}$, only two out of 12 subjects did so in the 'back' condition (Fisher's exact test: $\mathrm{N}=24 ; P<$ .0001). Whereas none of the subjects in the 'front' condition crossed the threshold line (Figure 1a), all 10 subjects in the 'back' condition that did not stay in front of the midline moved around the human by crossing the threshold line during the duration of $5 \mathrm{~s}$ ('back approach').

\section{Experiment 1.2: Head orientation}


179 Experiment 1.1 showed that goats alter their approach behaviour depending on whether a human

180 is orienting his front or back towards the subjects. Using a similar setup, we here investigated

181 whether goats also alter their behaviour depending only on the head orientation of a human.

182

183 Procedure

184 The experimenter approached a focal subject that was separated from other groups by about 5-

$18510 \mathrm{~m}$. He then proceeded to get its attention by calling 'Come here'. As soon as the goat 186 approached, a trial started. When the goat approached as close as $2 \mathrm{~m}$ towards the experimenter, 187 he either kept his front and head oriented towards the subject ('front') or turned his head 90 188 degrees to the left or right ('head away'), respectively (Figure 1b). During both conditions, the hands of the experimenter were behind his back to avoid inadvertently cueing the tested subject. A total of 27 trials were conducted. Three goats had to be excluded because they stopped approaching the experimenter, leaving 24 successful approach trials. Twelve subjects received the 'front' condition and the other 12 subjects received the 'head away' condition. Head orientation in the 'head side' condition was counterbalanced for the left and right side. Goats were never rewarded during trials.

Data scoring and analysis

Approach behaviour of the goats was scored live. Because goats often moved in front of the human when not rewarded instantly, we used a slightly different criterion compared to Experiment 1a. In this experiment, the experimenter scored the behaviour of the goats in their initial approach orientation. If the goats approached the experimenter in the middle, this was scored as 'front approach'. If the goats approached the experimenter from the left or the right side by crossing a threshold line with an angle of about 90 degrees on each side of the experimenter, this was scored as 'side approach' (Figure 1b). Fisher's exact test was used to compare the amount of both approach behaviours in the two different conditions. 
206 Results

207 There was no difference in approach behaviour between the two conditions. Eleven of 12 subjects 208 in the 'front', and 8 out of 12 in the 'head away' condition approached the experimenter from the 209 front and not the side (Fisher's exact test: $\mathrm{N}=24 ; P=.32$ ). From the four subjects that approached 210 the side of the experimenter in the 'head away' condition, only two did so for the same side the

211 experimenter was facing. Notably, none of the goats instantly moved behind the experimenter to 212 approach his hands in order to receive food. 
213 Experiment 2: Choice behaviour in the field

214

215 In Experiment 1.2, goats did not differ in their approach behaviour when a human experimenter

216 was looking at them compared to when he was looking to the side. However, goats may have just

217 avoided additional movement or preferred to remain in front of the experimenter because they

218 previously experienced humans moving their head frequently while living at the study site.

219 Therefore, we conducted a second experiment, in which the energetic effort for indicating a

220 preference for either an attentive or a non-attentive person was equal. In Experiment 2, we used

221 a modified test paradigm to cross-validate the findings from Experiment 1. In this experiment, we

222 used two experimenters, one paying attention to the subject while another one remained

223 inattentive. Goats were free to approach either of the experimenters.

224

225 Experiment 2.1: Body orientation

226

227

Procedure

228 Two experimenters approached a focal subject that was separated from other groups by about 5

$229-10 \mathrm{~m}$ and took position (see Figure 2a). They then proceeded to get its attention by calling

230 'Come here'. As soon as the goat approached, a trial started. When the goat approached as close

231 as $4 \mathrm{~m}$ to the experimenters, one experimenter turned his/her back towards the subject whereas

232 the other experimenter remained with his/her body and head oriented to the subject. Side and

233 identity of the attentive person was assigned in a pseudo-randomised manner. A total of 29 trials

234 were conducted. Five goats had to be excluded because they stopped approaching the

235 experimenter or their choice was ambiguous, e.g. standing in the middle of both experimenters,

236 leaving 24 successful approach trials. Goats were never rewarded during trials. 


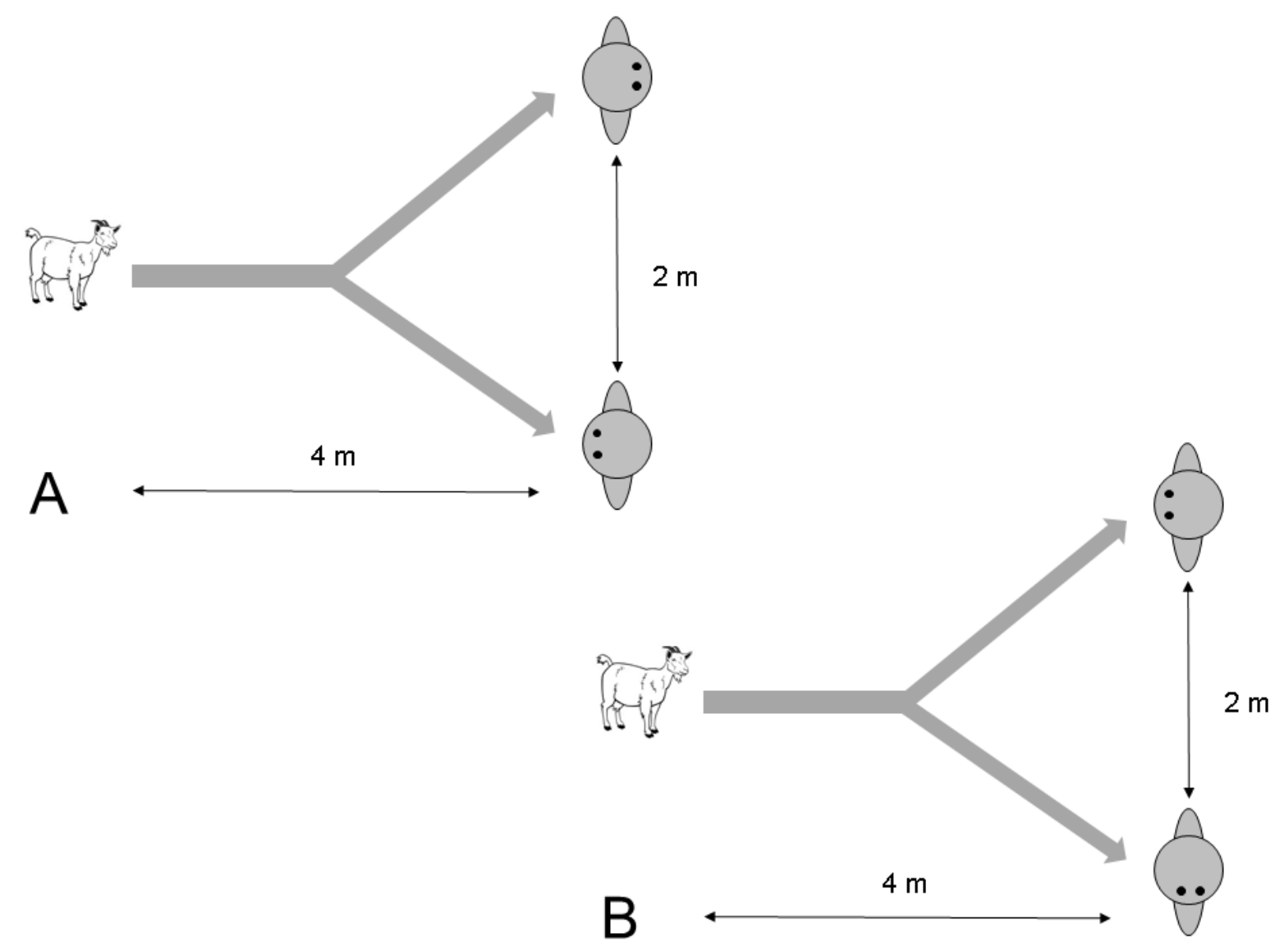

Figure 2. Setup of the choice task in a) Experiment 2.1 and b) Experiment 2.2. After a test subject started to approach the experimenters from a distance of about $4 \mathrm{~m}$, one of them either turned his/her body (Experiment 2.1) or head (Experiment 2.2) away from the subject.

242

Data scoring and analysis

Behaviour of the goats was recorded live. If a goat approached the attentive person, this choice was scored as 'correct'. Both experimenters had to agree that the focal subject approached one of them. Approach behaviour was unambiguous in all trials. To analyze preferences in the choice behaviour of goats, a binomial test was conducted in which the number of approaches to the attentive person was compared to chance level (50\%). 
251 Goats showed a preference for the attentive experimenter $(\mathrm{n}=24 ; \mathrm{K}=22 ; P<0.001$, two-tailed).

252 There was no side preference $(\mathrm{n}=24 ; \mathrm{K}=14 ; P>0.5$, two-tailed $)$ and no preference for one of

253 the experimenters $(\mathrm{n}=24 ; \mathrm{K}=14 ; P>0.5$, two-tailed).

254

255 Experiment 2.2: Head orientation

256

257 Procedure

258 Two experimenters approached a focal subject that was separated from other groups by about 5

$259-10 \mathrm{~m}$ and took position (see Figure $2 \mathrm{~b}$ ). They then proceeded to get its attention by calling

260 'Come here'. As soon as the goat approached, a trial started. When the goat approached as close

261 as $4 \mathrm{~m}$ to the experimenters, one experimenter turned his/her head away from the subject

262 whereas the other experimenter remained with his/her head oriented to the subject. All other

263 conditions were the same as in Experiment 2.1. A total of 30 trials were conducted. Six goats had

264 to be excluded because they stopped approaching the experimenter or their choice was

265 ambiguous, e.g. standing in the middle of both experimenters, leaving 24 successful approach

266 trials. Goats were never rewarded during trials.

267

268

Data scoring and analysis

269

Same as in Experiment 2.1.

270

271 Results

272 Goats showed no preference for either the attentive or the non-attentive experimenter $(n=24 ; K$

$273=13 ; P=0.83$, two-tailed $)$. There was no side preference $(\mathrm{n}=24 ; \mathrm{K}=15 ; P>0.3$, two-tailed $)$ and

274 no preference for one of the experimenters $(\mathrm{n}=24 ; \mathrm{K}=13 ; P>0.5$, two-tailed $)$.

276 Experiment 2.3: Hand orientation 
278 In Experiment 2.1., we could not rule out hand orientation as a confounding factor and thus 279 conducted a control experiment to investigate if the position of the hands (front or back) influenced 280 the choice behaviour of the goats.

Procedure

283 Two experimenters approached a focal subject that was separated from other groups by about 5 $284-10 \mathrm{~m}$ and took position. They then proceeded to get its attention by calling 'Come here'. As soon 285 as the goat approached, a trial started. When the goat approached as close as $4 \mathrm{~m}$ to the experimenters, both remained with their body and head oriented forward, while one experimenter placed his/her hands towards his/her back, whereas the hands of the other experimenter remained in front. All other conditions were the same as in Experiment 2.1. A total of 17 trials were conducted. Five goats had to be excluded because they stopped approaching the experimenter or their choice was ambiguous, e.g. standing in the middle of both experimenters, leaving 12 successful approach trials. Goats were never rewarded during trials.

292

293

Data scoring and analysis

294

Same as in Experiment 2.1.

295

296

Results

297 Goats showed no preference for either experimenter presenting the hands or the experimenter 298 covering the hands $(\mathrm{n}=12 ; \mathrm{K}=7 ; P=0.77$, two-tailed). There was no side preference $(\mathrm{n}=12 ; \mathrm{K}$ $299=9 ; P>0.1$, two-tailed $)$ and no preference for one of the experimenters $(\mathrm{n}=12 ; \mathrm{K}=7 ; P>0.5$, 300 two-tailed). 
301 Experiment 3: Choice behaviour in a controlled setting

302

303 In Experiment 1 and 2, goats showed a preference for humans that oriented their body and head,

304 but not head only, towards them. The negative results for differentiating the head orientation may

305 be a product of confounding factors that may have influenced decision making of the goats in the

306 previous experiments, e.g. distracting factors like environmental noise and nearby conspecifics,

307 or their specific motivation to approach the human. Because subjects could move freely, we were

308 not able to control for environmental disturbances and the position of conspecifics, which may

309 have biased their decision making. In terms of their motivation, we could not exclude whether

310 goats approached humans for other reasons than to receive a reward. For example, goats

311 sometimes rubbed themselves against the experimenter's clothing (pers. obs.), which would only

312 require the presence but not the attention of the human. To account for this, we conducted a third

313 and last experiment in a controlled setting. Prior to testing, subjects received food rewards while

314 they were trained to approach two human experimenters. During test trials, subjects had the

315 opportunity to approach one of two experimenters; one paid attention while the other was either

316 orienting her head away from the subject or closed her eyes (Proops \& McComb, 2010; Nawroth,

317 Ebersbach \& von Borell, 2013). In addition, we investigated whether goats understand the role of

318 occlusion, by either holding a big blind in front of the face or a small blind in front of the eyes of

319 one of the two experimenters (Flombaum \& Santos, 2005).

320

321 Procedure

322 The experiment was carried out in a temporary test arena, which we set up within the normal

323 daytime range of the goats. Goats were individually transferred to a test arena. During training

324 trials, the subject was brought to the start position at the entrance of the arena, held on a leash.

325 Two experimenters were positioned $4 \mathrm{~m}$ away from the starting point, kneeling, at the other side

326 of the arena. When both experimenters took position, the goat was released from the leash and 
327 was free to approach the experimenters and to receive the reward that they offer. To prevent the

328 goats developing a preference for one of the experimenters, the reward was administered jointly

329 by crossing over their arms and holding out their hands together with a piece of food (pasta) in

330 the middle of both of their hands. The experimenters also swapped sides between each trial.

331 Eighteen subjects were given an introductory training phase in which experimenters faced

332 forwards when giving a reward ('attentive training', Figure 3a). Another 18 goats received a

333 different training phase in which the experimenters were not attentive to the subjects and adopted

334 body postures that were not repeated in the test trials ('non-attentive training', Figure $3 b$ ). In this

335 phase, the experimenters kneeled at 90 degrees from the subject facing each other with their

336 hands outstretched together and a reward held in their hands. If necessary, goats were brought

337 on a leash to the experimenters in the first training trial. If subjects did not approach the

338 experimenter after $1 \mathrm{~min}$, a training trial was aborted. After a maximum of five training trials, all

339 but four goats instantly and reliably approached the experimenters and thus proceeded to the test 340 trials.

341

A

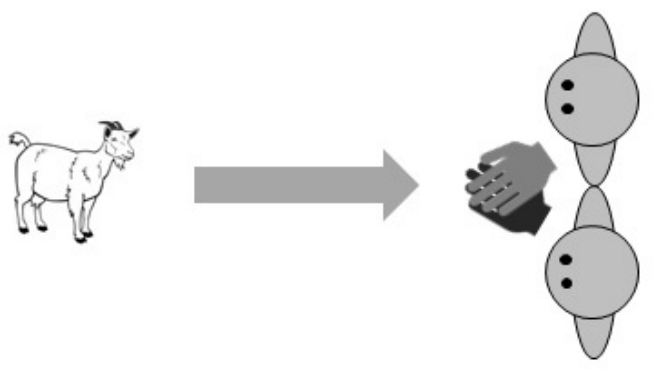

B

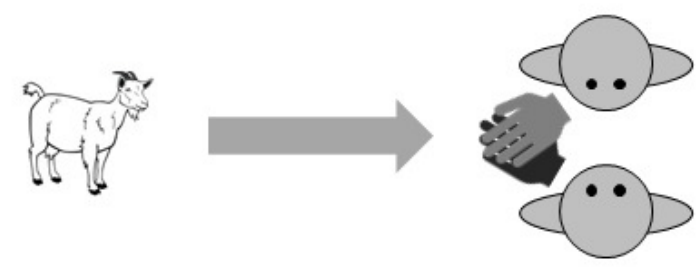


343 Figure 3. Images of the two training conditions in Experiment 3 a) attentive training b) non-

344 attentive training. A reward was administered jointly by both experimenters by crossing over their

345 arms and holding out their hands together with a piece of food (pasta) in the middle of both of

346 their hands

348 The procedure was the same as in the training trials, except that each experimenter took place in 349 a separate corner of the arena at $5 \mathrm{~m}$ from the starting point and $2.5 \mathrm{~m}$ away from each other.

350 Both experimenters differed in their degree of attention towards the subject. While one

351 experimenter paid attention to the goat, the other one had her attention oriented away from the

352 subject or her visual access was occluded. Four different test conditions were administered 353 (Figure 4):

354

A) Head away - both experimenters oriented their bodies to the front while one looked to the front, whereas the other one turned her head away

B) Eyes closed - both experimenters oriented their bodies and heads to the front, while one closed her eyes and the other remained with eyes open

C) Covered head - both experimenters oriented their bodies and heads to the front, while one covered the whole face and the other covered the chest with a blind $(28 \mathrm{~cm} \mathrm{x} 24 \mathrm{~cm})$

D) Covered eyes - both experimenters oriented their bodies and heads to the front, while one covered the eyes and the other covered the mouth with a blind $(28 \mathrm{~cm} \times 11 \mathrm{~cm})$

Each subject received one session of testing included four test trials, one for each condition. Conditions were counterbalanced for side (left/right) and experimenter (E1/E2). Goats were never rewarded during test trials. To ensure motivation, goats received a rewarded training trial after each test trial (delivered by the same experimenters as the initial training trials). 


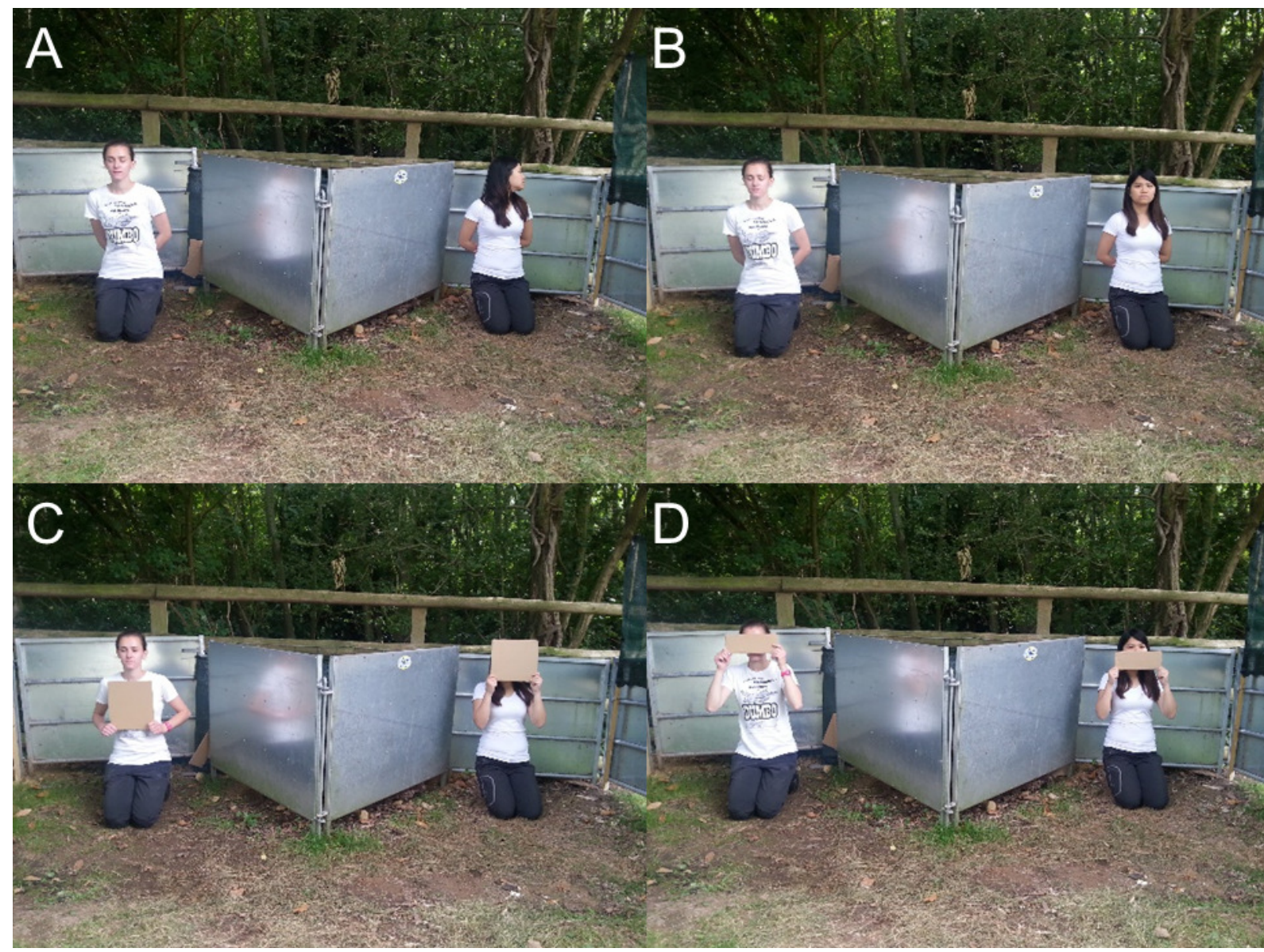

370 Figure 4. Images of the different test conditions in Experiment 3 a) Head away b) Eyes closed c)

371 Covered head d) Covered eyes.

Data scoring and analysis

374 Trials were scored live and were video recorded (Sony DCR-SX33E camcorder). We analysed goat choice and latency to approach. Latency times were defined as the time between a subject's first step from the starting position and the time it approached one of the two experimenters. An approach was defined as the goat getting as close as $15 \mathrm{~cm}$ to one of the experimenters with the head raised towards them. A second observer coded $25 \%$ of the test trials. Inter-observer reliability for choice (Cohen's $k=1.00)$ and latency to approach (Spearman rank correlation; $r_{\mathrm{s}}=$ 0.948; $P<0.001$ ) was excellent. Preference for the attentive or the non-attentive person, effect of experimenter identity and side preferences were calculated using the binomial test for choice 
382 behaviour of goats. Effects of goat sex and of the different warm-up types on choice behaviour 383 were analysed using Fishers Exact Test. Data for latency times were positively skewed and so 384 were $\log _{10}$ transformed. The potential effects of condition and response accuracy 385 (correct/incorrect) on the latency to approach an experimenter were analysed as fixed factors in 386 a Linear Mixed Model. Alpha level was set at 0.05 in all comparisons.

Results

389 Four subjects had to be excluded because they did not reliably approach the experimenters after 3905 training trials. This left 16 subjects with the attentive and 16 subjects with the inattentive training. One of the subject showed a strong side bias in all trials and was therefore excluded from further analysis. One subject did not make any choice after 1 min in the 'Head away' and 'Eyes closed' condition, another subject did not respond in time in the 'Covered head' condition. The training procedure, with either attentive or non-attentive experimenters, had no significant effect in any of the test conditions (Table 1). In test trials, goats did not show a preference for the attentive person when the other person looked away from the subject ('Head away'; $\mathrm{n}=30 ; \mathrm{K}=16 ; P=0.856$, Figure 5). There was a significant preference for the attentive person compared to the one that closed their eyes ('Eyes closed'; $\mathrm{n}=30 ; \mathrm{K}=21 ; P=0.043$, Figure 5 ). In addition, goats preferred to approach the attentive person compared to a person that covered the face with a blind 400 ('Covered head'; $\mathrm{n}=30 ; \mathrm{K}=23 ; P=0.005$, Figure 5), but not when the other person was covering the eyes ('Covered eyes'; $n=31 ; K=18 ; P=0.473$, Figure 5). We found no effect of sex (Fisher's Exact Test; $P=0.83)$, experimenter identity $(\mathrm{n}=121 ; \mathrm{K}=68 ; P=0.2)$ or side $(\mathrm{n}=121 ; \mathrm{K}=63 ; P$ $=0.72$ ) on choice behaviour of goats. Latency times to approach an experimenter did not vary as a function of performance $\left(F_{1,110}=1.173 ; P=0.281\right)$ or condition $\left(F_{3,106}=0.610 ; P=0.610\right)$. No interaction effect was found $\left(F_{3,106}=1.987 ; P=0.120\right)$. 
409 Table 1. Comparison of absolute and relative choices of goats for attentive humans given the 410 different training trials with either attentive or non-attentive experimenters

\begin{tabular}{lccccr}
\hline \multicolumn{1}{c}{ Condition } & \multicolumn{2}{l}{ Attentive training } & Non-attentive training & FET $(P)$ \\
\hline Head away & $6 / 14$ & $43 \%$ & $10 / 16$ & $63 \%$ & 0.46 \\
Eyes closed & $11 / 14$ & $79 \%$ & $10 / 16$ & $63 \%$ & 0.44 \\
Covered head & $11 / 15$ & $73 \%$ & $12 / 15$ & $80 \%$ & 1.00 \\
Covered eyes & $8 / 15$ & $53 \%$ & $10 / 16$ & $63 \%$ & 0.72 \\
\hline Total & $36 / 58$ & $62 \%$ & $42 / 63$ & $67 \%$ & 0.70 \\
\hline
\end{tabular}

411

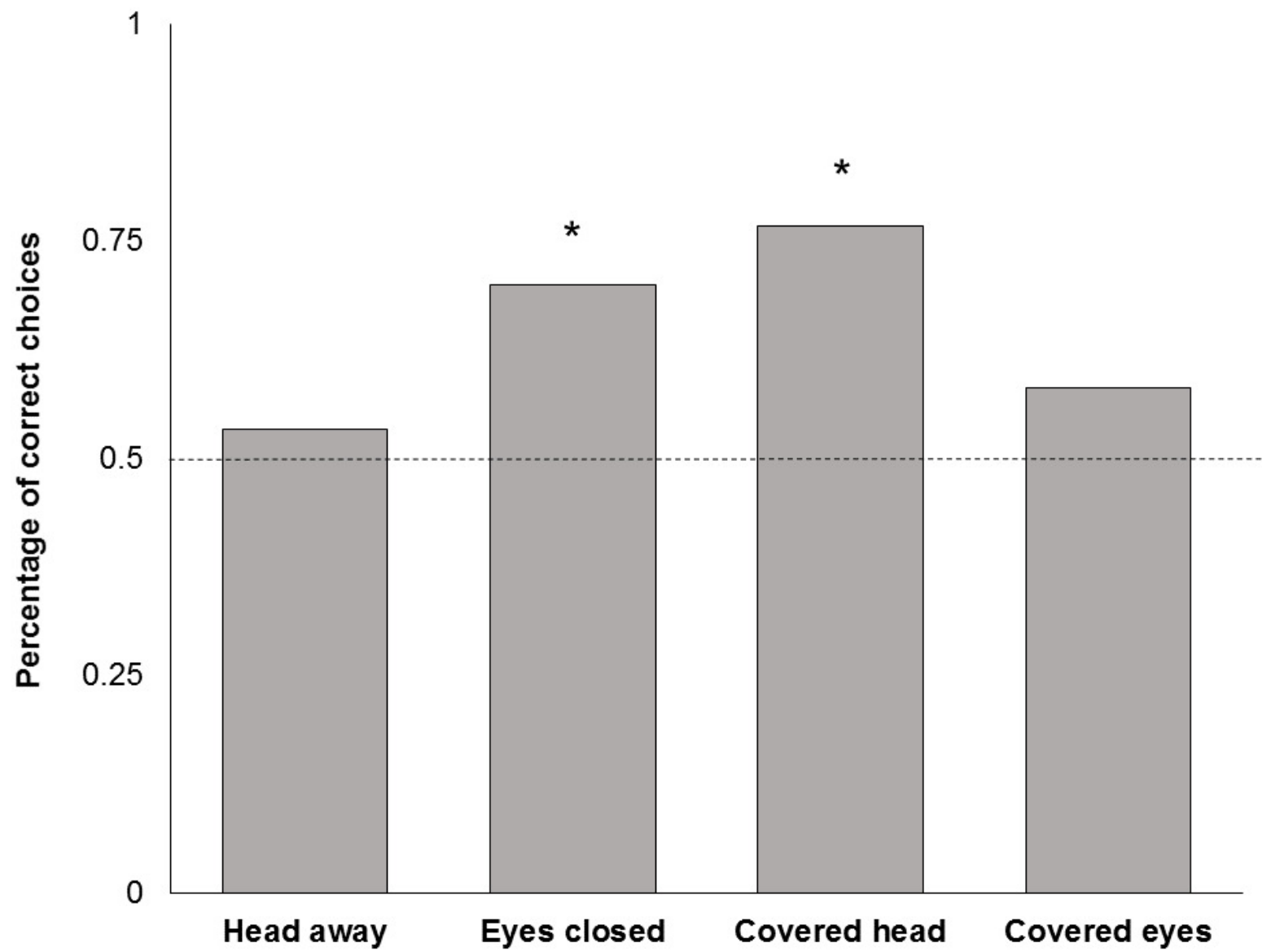

Figure 5. Relative number of choices for the attentive person by goats in the four test conditions. $414{ }^{*} \mathrm{P}<0.05$ (binomial test, two-tailed) 


\section{Discussion}

417

418 In a series of three experiments, we investigated whether domestic goats that are habituated to

419 human presence show a preference to approach an attentive compared to a non-attentive person.

420 Experiment 1 and 2 took advantage of the general approach behaviour of goats towards humans

421 at the study site. The results of these experiments show that goats actively try to position

422 themselves where a human is likely to notice them, and prefer to approach an experimenter who

423 orients his/her body towards them. However, they showed no preference in their approach and

424 choice behaviour when only the head orientation was given as a cue for the attentional stance.

425 Experiment 3 was conducted in a more controlled setting and confirmed the lack of preference

426 when only the head orientation of a human was altered. In addition, goats in this last experiment

427 preferred to approach a person whose face was not occluded and whose eyes were not closed,

428 indicating that they rely on cues other than head orientation when attributing attention. Contrary

429 to previous studies in horses and pigs that reported an effect of test condition and/or performance

430 on approach latencies (Proops \& McComb, 2010; Nawroth, Ebersbach \& von Borell, 2013), we

431 did not find a difference in the approach times of goats in our experiment. Our results show that

432 animals domesticated for production rather than companionship show differences in their

433 approach and choice behaviour depending on human attentive states (Hare et al., 2002; Nawroth,

434 Brett \& McElligott, 2016).

435

436

Contrary to previous research, all three experiments indicate that goats do not pay attention to

437 the head direction of a human experimenter. While it has been shown that goats decrease their

438 anticipatory behaviour in a food-anticipation paradigm when a person is directing their head away

439 from them (Nawroth, von Borell \& Langbein, 2015, 2016), we could not find behavioural

440 differences in our subjects. It is possible that this non-preference might be due to their specific

441 experience with humans. Goats at our study site interact with humans on a daily basis and are 
442 used to receiving food directly, although the human head is not necessarily in the direction of the

443 goat at that time. This might have altered their general anticipation of receiving food when

444 approaching humans that differ in their attentional stance. Alternatively, goats may not have

445 interpreted the human with its head turned away as an 'inattentive' subject. Goats, as animals

446 with laterally positioned eyes, might still be able to pay attention to events and subjects even

447 though their head is averted from those. Thus, head orientation might not be a reliable cue of

448 attention for goats and other ungulates. This explanation is partially in line with the finding that

449 goats can use human pointing gestures, but not human head orientation, to find a hidden food

450 reward (Kaminski et al., 2005; Nawroth, von Borell \& Langbein, 2015).

451

452 The first two experiments showed that goats evaluate the body orientation of the experimenter

when approaching a human or choosing between two experimenters. A control test showed that goats do not simply prefer to approach the experimenter whose hands were visible. Our results validate previous findings in similar experiments on goats (Nawroth, von Borell \& Langbein, 2015; Nawroth, Brett \& McElligott, 2016), which show that goats alter their behaviour depending on human body orientation. Body orientation is a more salient cue than head orientation alone (Emery, 2000). Similar results have been obtained for dogs (Call et al., 2003) and primates (Flombaum \& Santos, 2005; Bourjade et al., 2014).

Although goats did not alter their behaviour depending on head orientation, they preferred to approach a human that was not covering her face behind a blind. This indicates that, although the head direction might not be taken into account when making a choice, the human head itself conveys crucial information for goats (Tate et al., 2006). However, goats did not prefer to approach the person that was not covering her eyes with small blinds. It is possible that this lack of preference might be because both experimenters partially covered their faces with the small blinds (eyes vs mouth), and thus leading to an indifferent choice in our test subjects. 
Goats preferred to approach humans that had their eyes open vs closed, while the visibility vsnon-visibility of the area of the eyes did not alter their behaviour. This is a rather unexpected result, given their insensitivity to the head orientation in the same experiment. Several primate species (Flombaum \& Santos, 2005; Bourjade et al., 2014), but also dogs (Udell, Dorey \& Wynne, 2011) and horses (Proops \& McComb, 2010), have been found to be sensitive to open vs closed eyes of human. However, all these studies showed also that subjects considered the human head orientation as crucial when attributing attention. It is possible that our subjects were distracted by the small blinds, paying more attention to the blind rather than to the eye visibility. Goats might also have been sensitive to the eyes closed, but not to the eyes covered, because the previous reflects a more naturalistic setting. Future studies need to further examine when and how evaluate eye visibility.

In conclusion, our results provide evidence that species domesticated for production are sensitive to subtle human cues, such as whether eyes are open or closed. Our lack of evidence for goats' interpretation of human head orientation as a cue to their attentional stance demands further evaluation. We propose that ontogenetic factors such as previous experience with humans might play a crucial role in the development of human-directed behaviour.

\section{Acknowledgments}

We thank Luigi Baciadonna, Jemma Mary Brett, Pamela Prentice and Fang-Ting Wu for help during data collection, and the editor and the two reviewers for their very helpful comments on the manuscript. We also thank Robert Hitch and all the employees and volunteers of Buttercups

491 Sanctuary for Goats (http://www.buttercups.org.uk) for their excellent help and free access to the 492 animals. 
494

495

496

497

498

499

500

501

502

503

504

505

506

507

508

509

510

511

512

513

514

515

516

517

518

519

520

521

522

523

524

525

526

527

528

529

530

531

532

533

534

\section{References}

Agnetta B., Hare B., Tomasello M. 2000. Cues to food location that domestic dogs (Canis familiaris) of different ages do and do not use. Animal Cognition 3:107-112. DOI: $10.1007 / \mathrm{s} 100710000070$.

Association for the Study of Animal Behaviour. 2016. Guidelines for the treatment of animals in behavioural research and teaching. Animal Behaviour 111:I-IX.

Baciadonna L., Nawroth C., McElligott AG. 2016. Judgement bias in goats (Capra hircus): investigating the effects of human grooming. Peerj 4:e2485. DOI: 10.7717/peerj.2485.

von Bayern AMP., Emery NJ. 2009. Jackdaws respond to human attentional states and communicative cues in different contexts. Current Biology 19:602-6. DOI: 10.1016/j.cub.2009.02.062.

Beausoleil NJ., Stafford KJ., Mellor DJ. 2006. Does direct human eye contact function as a warning cue for domestic sheep (Ovis aries)? Journal of Comparative Psychology 120:269-279. DOI: 10.1037/0735-7036.120.3.269.

Bourjade M., Meguerditchian A., Maille A., Gaunet F., Vauclair J. 2014. Olive baboons, Papio anubis, adjust their visual and auditory intentional gestures to the visual attention of others. Animal Behaviour 87:121-128. DOI: 10.1016/j.anbehav.2013.10.019.

Bulloch MJ., Boysen ST., Furlong EE. 2008. Visual attention and its relation to knowledge states in chimpanzees, Pan troglodytes. Animal Behaviour 76:1147-1155. DOI: 10.1016/j.anbehav.2008.01.033.

Call J., Bräuer J., Kaminski J., Tomasello M. 2003. Domestic Dogs (Canis familiaris) Are Sensitive to the Attentional State of Humans. Journal of Comparative Psychology 117:257263.

Clucas B., Marzluff JM., Mackovjak D., Palmquist I. 2013. Do American Crows Pay Attention to Human Gaze and Facial Expressions? Ethology 119:296-302. DOI: 10.1111/eth.12064.

Emery NJ. 2000. The eyes have it: the neuroethology, function and evolution of social gaze. Neuroscience and biobehavioral reviews 24:581-604.

Flombaum JI., Santos LR. 2005. Rhesus Monkeys Attribute Perceptions to Others. Current Biology 15:447-452. DOI: 10.1016/j.cub.2004.12.076.

Hare B., Brown M., Williamson C., Tomasello M. 2002. The domestication of social cognition in dogs. Science 298:1634-1636. DOI: 10.1126/science.1072702.

Kaminski J., Riedel J., Call J., Tomasello M. 2005. Domestic goats, Capra hircus, follow gaze direction and use social cues in an object choice task. Animal Behaviour 69:11-18. DOI: 10.1016/j.anbehav.2004.05.008.

Kaminski J., Schulz L., Tomasello M. 2012. How dogs know when communication is intended for them. Developmental Science 15:222-32. DOI: 10.1111/j.1467-7687.2011.01120.x.

Kummer H. 1967. Tripartite relations in hamadryas baboons. In: Altmann SA ed. Social Communication Among Primates. Chicago: University of Chicago Press, 63-72.

Lakatos G., Gácsi M., Topál J., Miklósi A. 2012. Comprehension and utilisation of pointing gestures and gazing in dog-human communication in relatively complex situations. Animal cognition 15:201-13. DOI: 10.1007/s10071-011-0446-x. 
535

536

537

538

539

540

541

542

543

544

545

546

547

548

549

550

551

552

553

554

555

556

557

558

559

560

561

562

563

564

565

566

567

568

569

570

571

572

573

574

Miklósi Á., Pongracz P., Lakatos G., Topal J., Csanyi V. 2005. A Comparative Study of the Use of Visual Communicative Signals inInteractions Between Dogs (Canis familiaris) and Humans and Cats (Felis catus) and Humans. Journal of Comparative Psychology 119:179-186. DOI: 10.1037/0735-7036.119.2.179.

Miklósi Á., Soproni K. 2006. A comparative analysis of animals' understanding of the human pointing gesture. Animal Cognition 9:81-93. DOI: 10.1007/s10071-005-0008-1.

Nawroth C., von Borell E., Langbein J. 2015. "Goats that stare at men": dwarf goats alter their behaviour in response to human head orientation, but do not spontaneously use head direction as a cue in a food-related context. Animal Cognition 18:65-73. DOI: 10.1007/s10071-014-0777-5.

Nawroth C., von Borell E., Langbein J. 2016. "Goats that stare at men"-revisited: do dwarf goats alter their behaviour in response to eye visibility and head direction of a human? Animal cognition 19:667-672. DOI: 10.1007/s10071-014-0777-5.

Nawroth C., Brett JM., McElligott AG. 2016. Goats display audience-dependent human-directed gazing behaviour in a problem-solving task. Biology letters 12:20160283. DOI: 10.1098/rsbl.2016.0283.

Nawroth C., Ebersbach M., von Borell E. 2013. Are juvenile domestic pigs (Sus scrofa domestica) sensitive to the attentive states of humans? - The impact of impulsivity on choice behaviour. Behavioural Processes 96:53-58. DOI: 10.1016/j.beproc.2013.03.002.

Proops L., McComb K. 2010. Attributing attention: the use of human-given cues by domestic horses (Equus caballus). Animal Cognition 13:197-205. DOI: 10.1007/s10071-009-0257-5.

Proops L., Rayner J., Taylor AM., McComb K. 2013. The responses of young domestic horses to human-given cues. PLOS ONE 8:e67000. DOI: 10.1371/journal.pone.0067000.

Proops L., Walton M., McComb K. 2010. The use of human-given cues by domestic horses, Equus caballus, during an object choice task. Animal Behaviour 79:1205-1209. DOI: 10.1016/j.anbehav.2010.02.015.

Riedel J., Schumann K., Kaminski J., Call J., Tomasello M. 2008. The early ontogeny of human-dog communication. Animal Behaviour 75:1003-1014. DOI: 10.1016/j.anbehav.2007.08.010.

Sandel AA., MacLean EL., Hare B. 2011. Evidence from four lemur species that ringtailed lemur social cognition converges with that of haplorhine primates. Animal Behaviour 81:925-931. DOI: 10.1016/j.anbehav.2011.01.020.

Tate AJ., Fischer H., Leigh AE., Kendrick KM. 2006. Behavioural and neurophysiological evidence for face identity and face emotion processing in animals. Philosophical transactions of the Royal Society of London. Series B, Biological sciences 361:2155-2172. DOI: $10.1098 /$ rstb.2006.1937.

Udell M., Dorey N., Wynne C. 2011. Can your dog read your mind? Understanding the causes of canine perspective taking. Learning \& Behavior 39:289-302. DOI: 10.3758/s13420-0110034-6. 